Original Research Paper

\title{
Investigation into the Use of Electrochemical Extraction to Draw Gold from Refractory Ores
}

\author{
Bagdaulet Kenzhalyevich Kenzhaliyev, Zamzagul Duisenovna Dosymbaeva, \\ Renata Ramilevna Iskhakova and Essen Nurgalievich Suleimenov
}

Kazakh-British Technical University, Almaty, Republic of Kazakhstan

\author{
Article history \\ Received: 06-10-2015 \\ Revised: 07-11-2015 \\ Accepted: 09-11-2015 \\ Corresponding Author: \\ Bagdaulet Kenzalyevich \\ Kenzhaliyev \\ Kazakh-British Technical \\ University, Almaty, Republic \\ of Kazakhstan \\ Email: kenzhaliyevkz@gmail.com
}

\begin{abstract}
This paper studies the possibility of extracting gold by electrochemical leaching through the use of a sodium thiosulfate solution. In this regard, the requirements for environmentally sound technologies play a huge and vital role. Low extraction ratios and metal losses increase the cost of this process significantly and therefore it is necessary to reduce or prevent these disadvantages. Dissolution of gold at various electrolyte concentrations has been studied. The influence of current density on the leaching of gold within the solution has been investigated. The influence of the ratio S:L on gold extraction during electroleaching has been studied and the specific rate of gold leaching with different variations of the parameters has been defined. The sorption behavior of gold thiosulfate complexes on the anion exchanger AM-2B at various concentrations of sodium thiosulfate taken from model solutions has been studied. Research into the comparative study relating to the sorption of gold compounds from complex productive solutions used in electrochemical leaching has been conducted.
\end{abstract}

Keywords: Electrochemical Leaching, Electrode, Extraction, Gold, Leaching, Refractory Ore

\section{Introduction}

The majority of nonferrous metal ores deposits are developed over many decades, at the same time stocks of semi rich and relatively free milling ores are annually reduced, with the so-called refractory ores being sent on to concentration factories (refining factory) for further processing. These ores are complex in nature having high commercial value for both minerals of nonferrous metals (copper, zinc, lead) as well as for noble metals: Gold, silver, the platinum group metals and rare elements. Technologies used in the processing of these ores include, along with the release of concentrates of nonferrous metals, the extraction of noble metals.

Extraction throughout the world is ever increasing with regards to raw materials with low contents of valuable components with complex material composition, increasing the requirements during processing. This means that more advanced technological schemes, as well as highly efficient and cost-effective methods of extraction of nonferrous and noble metals are required (Parga et al., 2012) and exactly through greater involvement and technical innovation in the extraction of complex refractory gold and goldbearing ores perhaps, in the future, we can provide the main growth of gold production in the world (Adams, 2005; Vignes, 2011).

In the present paper the possibility of extracting gold by electrochemical leaching using a solution of sodium thiosulfate has been studied. In this regard, the requirements for environmentally sound technologies play a significant role. Low extraction ratios and metal losses leads to higher prices of ongoing processes. Therefore it is necessary to prevent these disadvantages.

\section{Literature Review}

Kholmogorov et al. (2002a) concluded that thiocyanate is an "effective lixiviant for gold in acidic conditions, increasing the rate of dissolution, which is comparable with the results obtained with thiourea". According to (Kholmogorov et al., 2002b), more than $95 \%$ of thiocyanate complexes of gold on carbon adsorbents and ion exchangers have been extracted from weak acidic solutions. Modern alternatives to cyanide leaching (McNulty, 2001) are ammonium thiosulfate (Breuer and Jeffrey, 2000; Aylmore, 2001) and 
thiocarbamide leaching (Ubaldini et al., 1998). Despite the proven effectiveness of thiourea as a gold leaching reagent (Lee et al., 1997; Yao et al., 1992; Tremblay et al., 1996) certain deficiencies of this method have been identified: Increased costs compared to cyanide; high reagent consumption; gold extraction requires many steps.

Thiosulphates of alkali metals are biodegradable and practically safe (Abbruzzese et al., 1995; Feng and Van Deventer, 2002), which permits their use in the geotechnologies of underground and heap leaching, they are cheaper than cyanide and they are more effective in the case of refractory carbon and copper-containing ores. Thiosulfate leaching has obvious advantages, when considering both technological and environmental parameters (Aylmore and Muir, 2001; Zipperian and Raghavan, 1988). The problem of reagents does not exist. This, along with the resources savings, is the main advantage of using thiosulfate technology which remains safe during all stages of technological conversion as well as ensuring staff health and safety. Currently, there are almost no examples of actual industrial use of thiosulfate leaching in the gold industry primarily due economic reasons.

Currently, the primary way of increasing the competitiveness and profitability of gold production is a combination of traditional mining technology with new technologies (Qingshuang et al., 1995; Balaz et al., 2000), heap and electrosorption leaching, electrochemical extraction (Zhou et al., 2009), hydrometallurgical repartitioning of solutions (Grosse et al., 2003) etc. However, capital costs for gold production remain high and the cost price of gold is constantly growing.

There are a large number of studies on the use of electro processing in the extraction of metals in solutions, however, the reactions when transferring

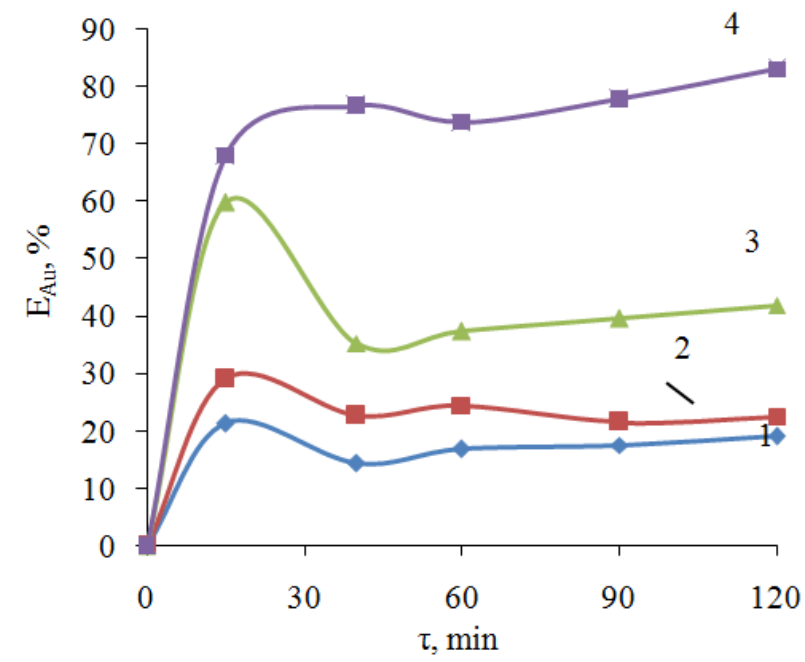

(a) metals in solutions of different chemical composition by electric current-electrochemical leaching (Kenzhaliev, 2014) occupy a special place in the studies of electrochemical processes.

\section{Materials and Methods}

Studies into the effects that the parameters of the electroleaching process have in gold extraction were carried out in a specially designed and constructed thermostatic reaction cell. The cell has a threeelectrode system. As the working electrode sulfur graphite was used, as the auxiliary electrode graphite electrodes were used with a silver chloride electrode serving as a reference electrode. Electroleaching was performed with sodium thiosulfate in an alkaline medium under various experimental parameters: Temperature $\left(25 ; 40 ; 50 ; 60^{\circ} \mathrm{C}\right)$, current density $\left(100,200,300\right.$ and $\left.400 \mathrm{~A} / \mathrm{m}^{2}\right)$, the concentration of the electrolyte $(0.1 ; 0.5 ; 1.0$ and 2.0 M) the ratio $S: L(1: 3 ; 1: 4 ; 1: 6 ; 1: 10)$. Study duration-2 $\mathrm{h}$.

During the experiment the samples were taken for analysis as well as the $\mathrm{pH}$ of the medium and electroconductivity-Eh and concentration of Dissolved Oxygen $\left(\mathrm{DO}_{2}\right)$ have been measured by using a SensIon 156 portable analyzer, made by "HACH" (USA).

\section{Results}

Defining the parameters when electrochemical leaching a gold solution. During electrochemical leaching the dissolution of metals at various concentrations of the electrolyte was observed. Dependence of the degree of gold extraction into the solution (a) and the specific rate of the gold leaching (b) are shown in Fig. 1.

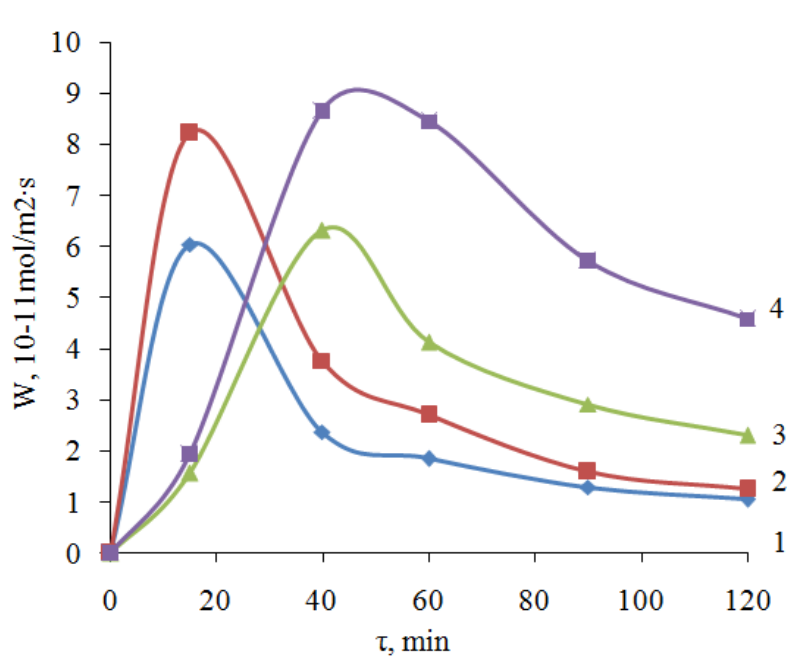

(b)

Fig. 1. The degree of gold extraction versus the concentration of the electrolyte (a) and the specific rate of gold leaching (b) Concentration levels of the electrolyte: 1-0.1, 2-0.5, 3-1.0 and 4-2.0 M 
The dependence of the change of oxygen concentration from the electrolyte concentration is shown in Fig. 2.

With a thiosulfate concentration of $0.1 \mathrm{M}$, maximum gold extraction is $21.4 \%$, the leaching of metals continues and the volume of the oxygen decreases, this is indirectly confirmed by the graph of the electrical conductivity from the electrolyte concentration shown in Fig. 3. Up to the 30 min mark of the process, the electric conductivity and the oxygen concentration are both decreasing. After 30 min, the electric conductivity begins to increase up to a value of $59.15 \mu \mathrm{S} / \mathrm{cm}$ by shifting additional components (leaching of metals) into the solution.

As can be seen in the figures, when the electrical conductivity of the solution decreases slightly and then increases it is likely due to changes in the concentration of the solution which is probably a result of the solution restructuring.

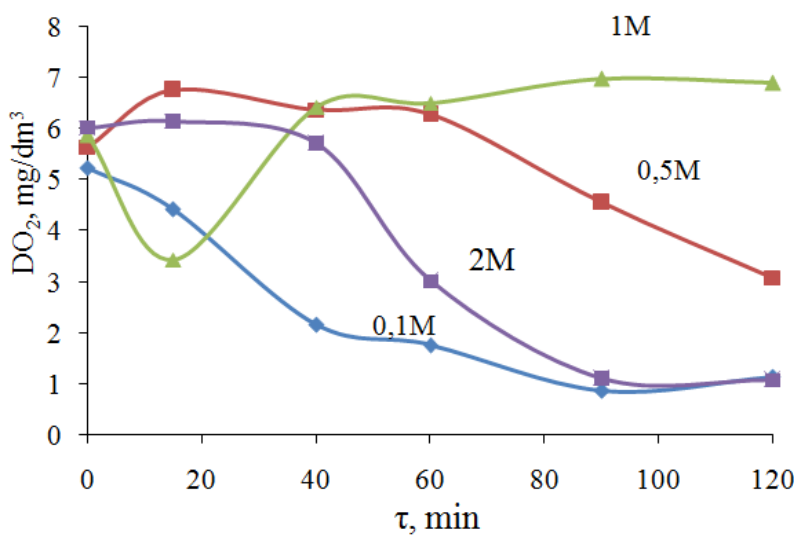

Fig. 2. The oxygen concentration variation versus the electrolyte concentration Concentration levels of the electrolyte: 1-0.1, 2-0.5, 3-1.0 and 4-2.0 M

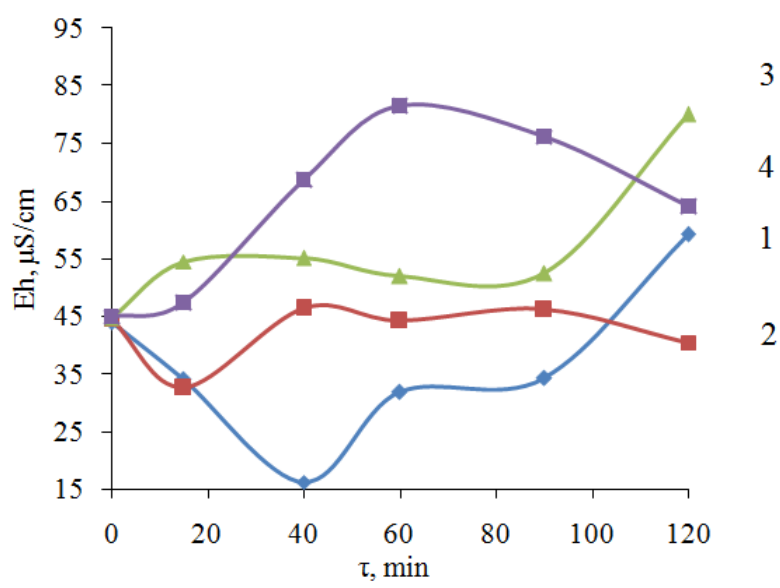

Fig. 3. The electric conductivity variation versus the electrolyte concentration Electrolyte concentration: 1$0.1,2-0.5,3-1.0$ and $4-2.0 \mathrm{M}$
Further studies have been conducted for determining the optimum current density using sodium thiosulfate with a concentration of $2.0 \mathrm{M}$ with different current densities: 100, 200, 300 and 400 $\mathrm{A} / \mathrm{m}^{2}$ (Fig. 4a). The results showed that the specific rate of gold leaching during the process increases sharply, namely within the first $40 \mathrm{~min}$ of the experiment, followed by a gradual decrease in the reaction rate as the process continues (Fig. 4b). Here the characteristics of dependences is the same with all current densities with the highest specific rate of gold leaching achieved with a density of $200 \mathrm{~A} / \mathrm{m}^{2}$ $\left(8.65 \cdot 10^{-11} \mathrm{~mol} / \mathrm{m}^{2} \cdot \mathrm{s}\right)$.

Results of the research into the extent of gold extraction from the concentrate depending on the $\mathrm{S}: \mathrm{L}$ ratio are shown in Fig. 5. As shown in Fig. 5b, the specific rates increased up to the $40 \mathrm{~min}$ mark and then declined, this is directly connected with the decreasing metal content in the initial product as well as with decreasing dissolved oxygen content, which is consumed in the oxidation process of metals. The influence that temperature has on the dissolution rate of gold and silver from the concentrate in the temperature ranges from 25 to $60^{\circ} \mathrm{C}$ has been studied. A solution with a concentration of $2.0 \quad \mathrm{M}$ $\mathrm{Na}_{2} \mathrm{~S}_{2} \mathrm{O}_{3} \cdot 5 \mathrm{H}_{2} \mathrm{O}$ was used. Results for the gold leaching are shown in Fig. 6 as an example.

The dependence of the change in the specific rate from leaching time is shown in Fig. 6b. The effectiveness of sorption extraction of thiosulfate gold complexes have been evaluated according to the values of the extraction degree (E, \%). Sorption isotherms have been obtained by method of variation in the molar ratio.

The next step was to study the effect of the ratio in the volume of the anion exchanger to the volume of the contacting solution $\left(\mathrm{V}_{\text {resin }}: \mathrm{V}_{\text {solution, }} \mathrm{S}: \mathrm{L}\right)$ on the overall sorption process. The effectiveness of sorption extraction on thiosulfate complexes of gold have been evaluated based on the values of the degree of sorption (extraction) (E, \%) (Fig. 8).

In the next stage of the work a comparative study into the sorption of gold compounds from complex productive solutions of electrochemical leaching has been conducted. The kinetic curves of sorption from productive solutions of electrochemical leaching are shown in Fig. 9.

The rates of sorption shown in Table 1 for solutions of electrochemical leaching correspond to the results on a comparative study of the sorption behavior of gold compounds and accompanying metals from technological solutions. 


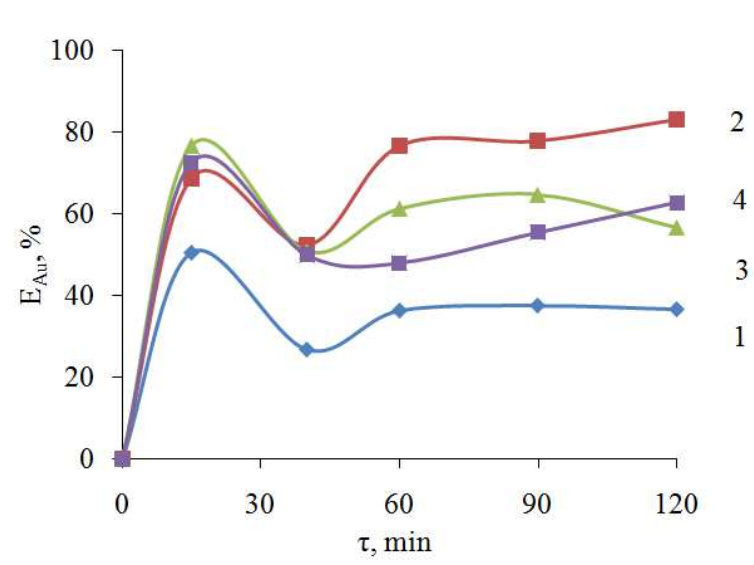

(a)

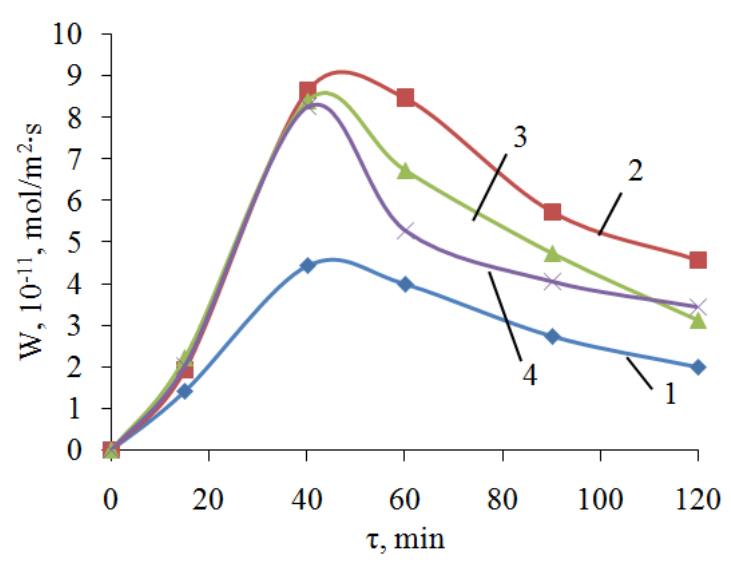

(b)

Fig. 4. The degree of gold extraction versus current density (a) and the specific rate of gold leaching (b) Current density: 1-100, 2$200,3-300$ and $4-400 \mathrm{~A} / \mathrm{m}^{2}$

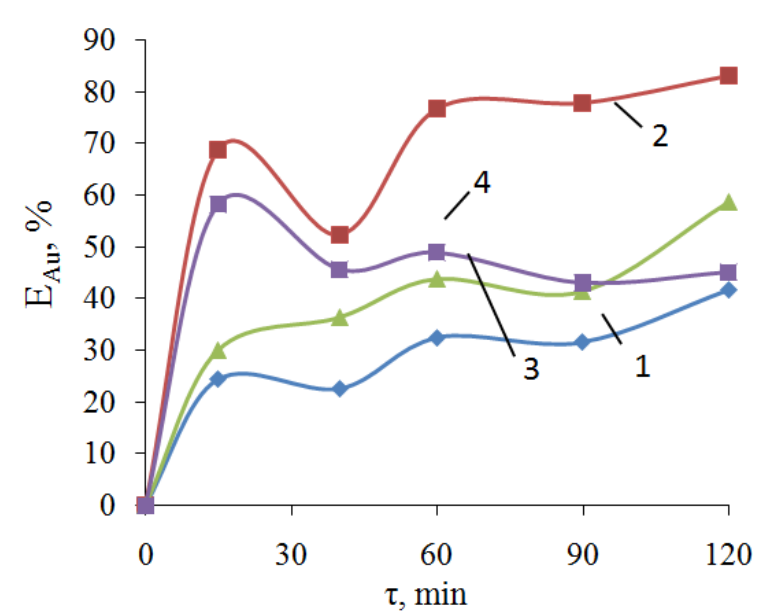

(a)

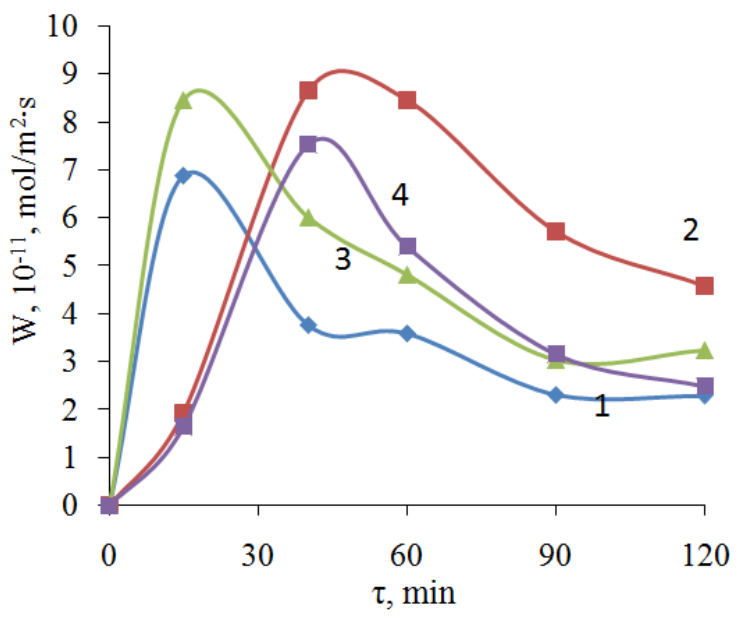

(b)

Fig. 5. The degree of gold extraction by ratio of S:L (a) versus the specific rate of gold leaching by ratio of S:L (b) Ratioof S:L : 1$1: 3 ; 2-1: 4 ; 3-1: 6 ; 4-1: 10 ; \mathrm{i}=200 \mathrm{~A} / \mathrm{m}^{2} ; \mathrm{t}=25^{\circ} \mathrm{C}$

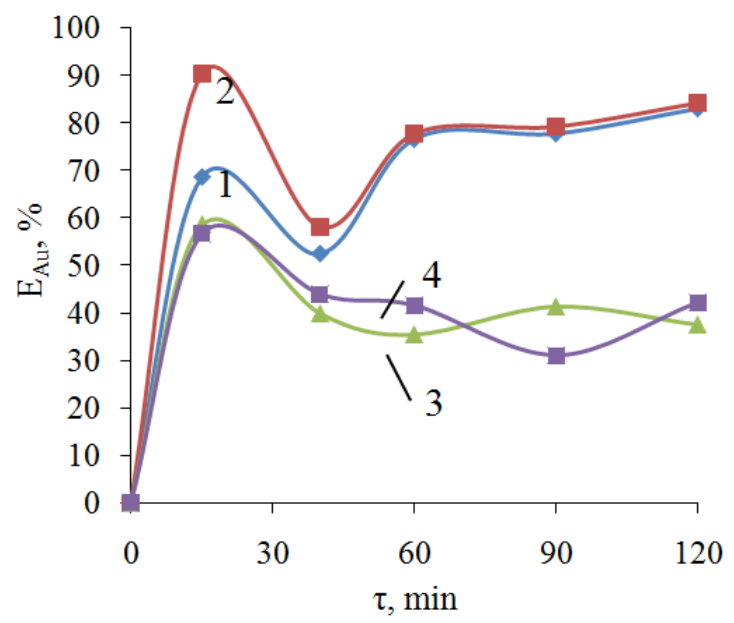

(a)

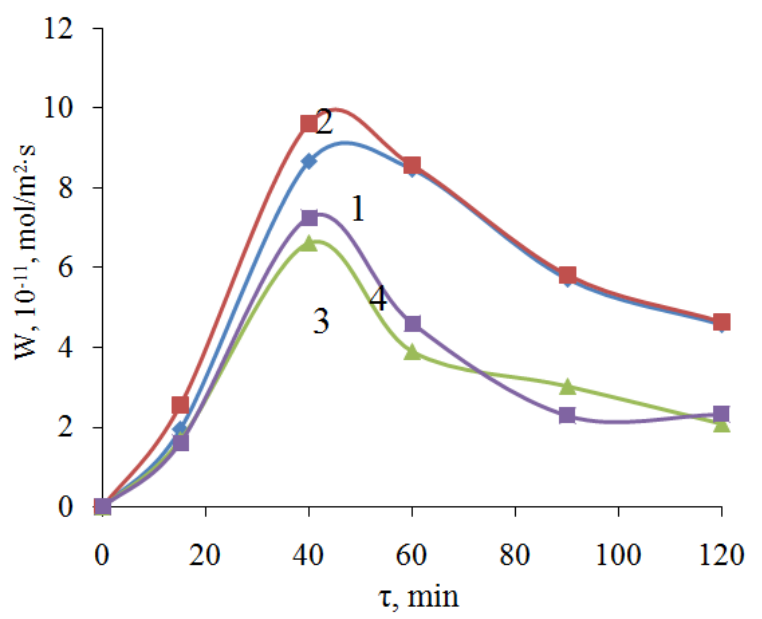

(b)

Fig. 6. The dependence of the degree of gold extraction by temperature (a) and the specific rate of gold leaching by temperature (b) Temperature: $1-25,2-40,3-50$ and $4-60^{\circ} \mathrm{C} ; \mathrm{S}: \mathrm{L}:=1: 4 ; \mathrm{i}=200 \mathrm{~A} / \mathrm{m}^{2}$ 


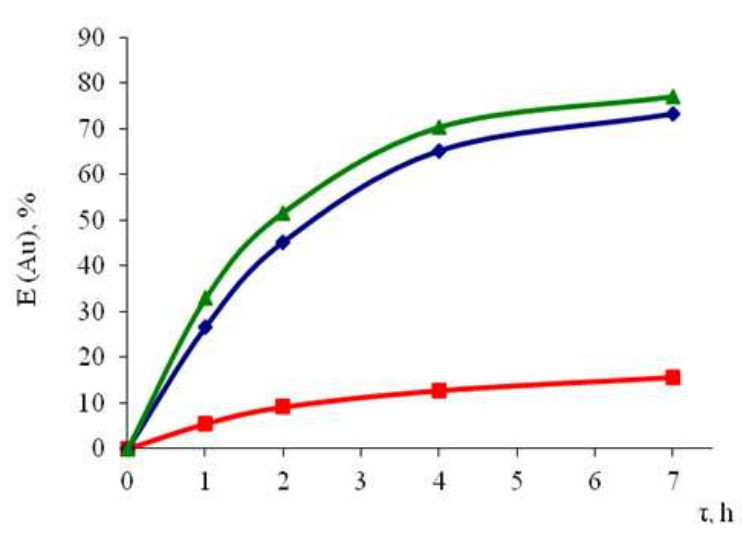

Fig. 7. The dependence of the degree of gold sorption (a) and silver (b) by concentration of sodium thiosulfate Concentration of $\mathrm{Na}_{2} \mathrm{~S}_{2} \mathrm{O}_{3}: \quad 1-0.1 \mathrm{~mol} / \mathrm{dm}^{3}, \quad 2-0.2$ $\mathrm{mol} / \mathrm{dm} 3,3-0.5 \mathrm{~mol} / \mathrm{dm}^{3} ; \mathrm{t}=25^{\circ} \mathrm{C}$

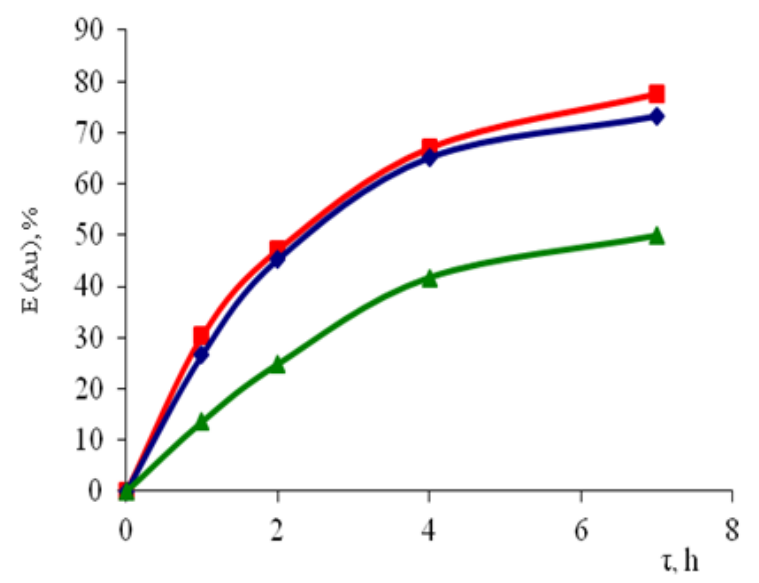

Fig. 8. The effect of the ratio $\mathrm{S}: \mathrm{L}$ on the degree of sorption of gold from model solutions S:L ratio: 1-1:200, 2-1:500, 3$1: 800$; concentration of $\mathrm{Na}_{2} \mathrm{~S}_{2} \mathrm{O}_{3}-0.2 \mathrm{~mol} / \mathrm{dm}^{3} ; \mathrm{t}=25^{\circ} \mathrm{C}$

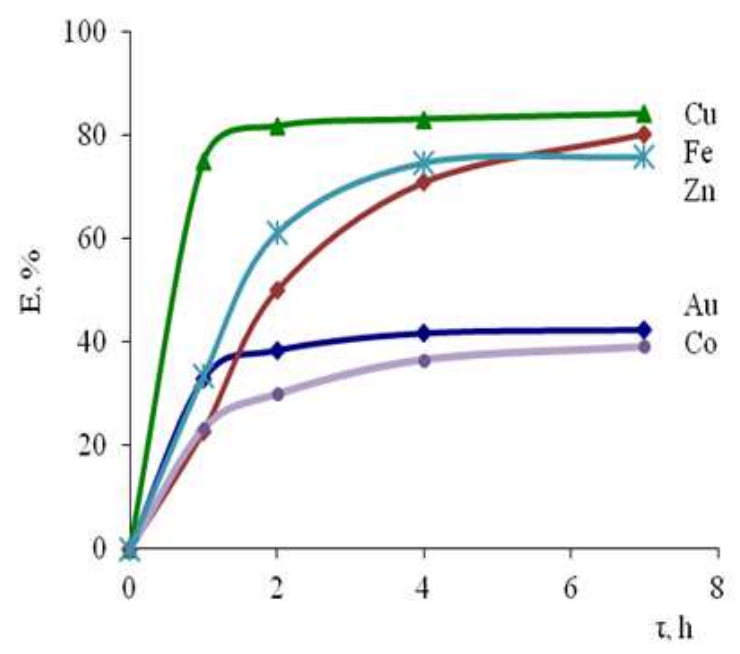

Fig. 9. The degree of sorption extraction of metals from the electrochemical leaching solution $\mathrm{S}: \mathrm{L}=1: 500, \mathrm{t}=25^{\circ} \mathrm{C}$
Table 1. The rates of sorption of compounds of gold, silver and nonferrous metals from electrochemical leaching solutions

The solution after electrochemical leaching

\begin{tabular}{lllll} 
Time, min & 60 & 120 & 240 & 420 \\
\hline $\mathrm{W}_{\mathrm{Au}} \cdot 10^{-10}, \mathrm{mg} \cdot \mathrm{eqv} / \mathrm{s}$ & 3,5468 & 1,9851 & 1,0550 & 0,6102 \\
$\mathrm{~W}_{\mathrm{Cu}} \cdot 10^{-10}, \mathrm{mg} \cdot \mathrm{eqv} / \mathrm{s}$ & 3633,40 & 1984,06 & 1008,50 & 583,31 \\
$\mathrm{~W}_{\mathrm{Fe}} \cdot 10^{-10}, \mathrm{mg} \cdot \mathrm{eqv}$ & 0,7587 & 0,8333 & 0,5907 & 0,3817 \\
$\mathrm{~W}_{\mathrm{Co}} \cdot 10^{-10}, \mathrm{mg} \cdot \mathrm{eqv} / \mathrm{s}$ & 0,3300 & 0,2124 & 0,1297 & 0,0793 \\
$\mathrm{~W}_{\mathrm{Zn}} \cdot 10^{-10}, \mathrm{mg} \cdot \mathrm{eqv} / \mathrm{s}$ & 319,9815 & 293,1660 & 179,3192 & 104,0458 \\
\hline
\end{tabular}

\section{Discussion}

As can be clearly seen, during the growth of gold extraction the concentration of oxygen is significantly reduced. At a concentration level of $0.1 \mathrm{M}$ gold extraction increases up to $14.34 \%$, at $0.5 \mathrm{M}$ up to $22.78 \%$, at $1.0 \mathrm{M}$ up to $35.33 \%$ and at a concentration of $2 \mathrm{M}$ up to $76.67 \%$ in the first $30 \mathrm{~min}$ of leaching and then gradually increasing to $82 \%$ (Fig. 1a) with the oxygen concentration beginning to decrease after $40 \mathrm{~min}$.

The specific rate at concentrations of $0.1 \mathrm{M}$ and $0.5 \mathrm{M}$ is increasing up to the $20 \mathrm{~min}$ mark of the leaching process and then reduces. At concentrations of $1.0 \mathrm{M}$ and $2.0 \mathrm{M}$ it is increasing up to $40 \mathrm{~min}$ and then reduces which characterizes the complexity of the process (Fig. 1b).

In carrying out leaching over a 15 min period with $0.1 \mathrm{M}$ and $2.0 \mathrm{M}$ thiosulphate sodium the specific rates of gold leaching were $6.04 \cdot 10^{-11} \mathrm{~mol} / \mathrm{m}^{2} \cdot \mathrm{s}$ and $8.44 \cdot 10^{-11} \mathrm{~mol} / \mathrm{m}^{2} \cdot \mathrm{s}$ respectively. With leaching using $0.5 \mathrm{M}$ and $1.0 \mathrm{M}$ thiosulphate sodium concentrations the specific rates of reactions were: $8.22 \cdot 10^{-11} \mathrm{~mol} / \mathrm{m}^{2} \cdot \mathrm{s}$ and $6.32 \cdot 10^{-11} \mathrm{~mol} / \mathrm{m}^{2} \cdot \mathrm{s}$ when leaching is carried out over a 40 min period.

At a concentration of $1.0 \mathrm{M}$ the oxygen concentration is reduced during the first $20 \mathrm{~min}$ then increases up to $6.98 \mathrm{mg} / \mathrm{dm}^{3}$. As seen on the curve, reprecipitation of gold on the electrode occurs. At a thiosulfate concentration of $0.5 \mathrm{M}$, the concentration of oxygen in the system has little connection with the extraction of gold in the system. At a concentration of $0.1 \mathrm{M}$, extraction of gold in the solution is low with the oxygen concentration dropping to a value of $0.87 \mathrm{mg} / \mathrm{dm}^{3}$.

With gold leaching by thiosulfate with a density of 100 and $300 \mathrm{~A} / \mathrm{m}^{2}$, values of the specific rate are $4.44 \cdot 10^{-11}$ $\mathrm{mol} / \mathrm{m}^{2} \cdot \mathrm{s}$ and $8.41 \cdot 10^{-11} \mathrm{~mol} / \mathrm{m}^{2} \cdot \mathrm{s}$ respectively. At $400 \mathrm{~A} / \mathrm{m}^{2}$ the specific rate of reactions is $8.26 \cdot 10^{-11} \mathrm{~mol} / \mathrm{m}^{2} \cdot \mathrm{s}$.

Research results showed that the specific rate of the process for all values of current densities at the initial time $\left(24 \cdot 10^{2} \mathrm{~s}\right)$ increases, then over time (from $24 \cdot 10^{2}$-to $\left.54 \cdot 10^{2} \mathrm{~s}\right)$ this indicator gets sharply reduced, which is connected with the reduction of metal content in the initial product sample as well as with the decreasing dissolved oxygen content, which has been consumed in the process of metal oxidation. Moreover there is a 
reduction in oxygen solubility with decreasing of $\mathrm{pH}$ levels in the solution. The specific rate of gold dissolution for all studied variants of electrochemical leaching had its maximum value in the first $2410^{2} \mathrm{~s}$ of the leaching process.

Influence of the $\mathrm{S}: \mathrm{L}$ ratio on the extraction of gold during electroleaching has been studied.

With a thiosulfate concentration of $0.1 \mathrm{M}$, maximum gold extraction is $21.4 \%$, the leaching of metals continues and the volume of the oxygen decreases, this is indirectly confirmed by the graph of the electrical conductivity from the electrolyte concentration shown in Fig. 3. Up to the 30 min mark of the process, the electric conductivity and the oxygen concentration are both decreasing. After $30 \mathrm{~min}$, the electric conductivity begins to increase up to a value of $59.15 \mu \mathrm{S} / \mathrm{cm}$ by shifting additional components (leaching of metals) into the solution.

As can be seen in the figures, when the electrical conductivity of the solution decreases slightly and then increases it is likely due to changes in the concentration of the solution which is probably a result of the solution restructuring.

As can be seen (Fig. 5a) the gold extraction increased during the first $20 \mathrm{~min}$ of leaching and then reduced. Maximum extraction was achieved with $\mathrm{S}: \mathrm{L}=1: 4$ and is $86.67 \%$ efficient. With $\mathrm{S}: \mathrm{L}=1: 3$ and $\mathrm{S}: \mathrm{L}=1: 6$ there was an increase in the extent of gold extraction as the oxygen concentration decreased and with a decrease in the extent of gold extraction, the oxygen concentration increased. This may indicate that the oxygen concentration in the system has little connection with the gold recovery system. At $\mathrm{S}: \mathrm{L}=1: 4$ with an increase in the extent of gold extraction, the oxygen concentration at the during the initial period increased, then decreased down to $3.41 \mathrm{mg} / \mathrm{dm}^{3}$.

As shown in Fig. 5b, the specific rates increased up to the 40 min mark and then declined, this is directly connected with the decreasing metal content in the initial product as well as with decreasing dissolved oxygen content, which is consumed in the oxidation process of metals.

It has been established that increasing the solution's temperature up to $60^{\circ} \mathrm{C}$ does not affect the efficiency of gold extraction in the solution. With temperatures of 25 , $40,50,60^{\circ} \mathrm{C}$, the maximum extraction level is 82.99 , $90.47,58.53$ and $56.67 \%$ respectively.

Research results show that the specific rate of the process for all temperatures at the initial time $\left(24 \cdot 10^{2}\right.$ s) increases, then over time (from $24 \cdot 10^{2}$-to $54 \cdot 10^{2} \mathrm{~s}$ ) this indicator is sharply reduced, which is connected with the reduction in the metal content of the initial product as well as with decreasing dissolved oxygen content, which has been consumed in the process of metal oxidation (Fig. 6b).

With this the maximum specific rate is reached and the results are as follows: At $40^{\circ} \mathrm{C}$ a rate of
$9.62 \cdot 10^{-11} \mathrm{~mol} / \mathrm{m}^{2} \cdot \mathrm{s}$. At 50 and $60^{\circ} \mathrm{C}$ the values of the specific rate are $6.6 \mathrm{~mol} / \mathrm{m}^{2} \cdot \mathrm{s}$ and $7.25 \mathrm{~mol} / \mathrm{m}^{2} \cdot \mathrm{s}$ respectively. The nature of the dependence is explained firstly by a gradual increase in the degree of saturation within the solutions, with gold and other impurity elements, that takes place during the course of the leaching process and secondly by the simultaneous reduction of the gold content in the samples.

The study of the sorption of gold from solutions by electrochemical leaching. In the modern gold extracting industry sorption method extraction of gold and silver is one of the most common hydrometallurgical operations. Ion exchange resins or activated carbons are used as sorbents (Kholmogorov et al., 2002b).

It is known that the process of dissolution of gold and silver can be written as the following equation:

$$
4 \mathrm{Au}+8 \mathrm{~S}_{2} \mathrm{O}_{3}^{2-}+\mathrm{O}_{2}+2 \mathrm{H}_{2} \mathrm{O} \rightarrow 4\left[\mathrm{Au}\left(\mathrm{S}_{2} \mathrm{O}_{3}\right)_{2}\right]^{3-}+4 \mathrm{OH}^{-}
$$

The main parameter of this process is the concentration of thiosulfate ions and, as a result of dissolution, sustained thiosulfate complexes of gold arise (I). The same complexes also are formed in the model solutions (Salarirad and Behnamfard, 2011).

The sorption of gold from the individual model thiosulfate solutions by the anion exchanger AM-2B in $\mathrm{OH}^{-}$form has been investigated. At the initial stage, the sorption behavior of thiosulfate complexes of gold on the anion exchanger AM-2B with various concentrations of sodium thiosulfate: $0.1,0.2$ and 0.5 $M$ were studied (Fig. 7). The results showed that sorption, in a solution of $0.1 \mathrm{M}$ sodium thiosulfate, is inefficient because a low degree of sorption (15\%) is achieved. The best results have been obtained in the experiments with a thiosulfate concentration of $0.2 \mathrm{M}$ : $\mathrm{E}_{\mathrm{Au}}=73.15 \%$ and $0.5 \mathrm{M}: \mathrm{E}_{\mathrm{Au}}=76.88 \%$ (Fig. 7).

It can be seen that further increases in concentration above $0.2 \mathrm{M}$ has little effect on the degree of sorption, as a result of this all further experiments were performed with solutions of thiosulfate containing $0.2 \mathrm{~mol} / \mathrm{dm}^{3}$.

The presented curves show that the maximum degree of gold extraction is $73.15 \%$, which is achieved at the ratio of $\mathrm{V}_{\text {resin }}: \mathrm{V}_{\text {solution }}=1: 500$. It is established that with a decrease of the volume of solution, the degree of sorption in turn gets reduced by a factor of 2 times, while an increase of the volume of the solution has an insignificant effect on the degree of sorption of gold (Fig. 8).

In addition to gold a large number of accompanying metals, which have high sorption susceptibility, are removed from the solution, which is the reason for the sharp decrease in the working capacity of the anion exchanger AM-2B on the target metal. In all experiments, the presence of impurity metals adversely affects the gold 
sorption process, reducing its degree of sorption by several times. The extent of sorption of gold reached $42 \%$.

From the presented dependencies it can be seen that with increasing degrees of sorption of impurity metals, the degree of sorption of gold reduces. The sorption behavior of copper in solutions of electrochemical leaching is similar to behavior observed in thiosulfate solutions: During the first hour of experiments copper gets almost completely sorbed-80\%. A high degree of sorption is achieved by other related elements: $75 \%$ of zinc is sorbed, $80 \%$ of iron and $35 \%$ of cobalt.

The results of the study showed that the specific rates in the process of sorption of metals from electrochemical leaching increases sharply during the initial period of time, namely, during the first $60 \mathrm{~min}$ of the experiment and, further to this there is a gradual decrease in the reaction rate. The maximum specific rate of sorption of gold from technological solutions of electrochemical leaching is achieved at an electric current of $200 \mathrm{~A}$. The nature of the dependence is explained firstly by the gradual increase in the degree of saturation of the anion exchanger with gold and nonferrous metals, which takes place during the process of sorption and secondly by the simultaneous decrease in the metal content of the solutions.

It has been shown that the presence of a large number of accompanying (associated) elements have a high sorption ability-this is the primary reason for the sharp decrease in the working capacity of the anion exchanger AM-2B on the target metals as it exerts a strong influence on the process of sorption of noble metals from complex productive solutions during electrochemical leaching.

In order to increase the maximum potential degree of sorption of gold and silver the pre-treatment (preliminary cleaning) of productive solutions, to reduce the quantity of impurity components, is recommended.

\section{Conclusion}

The purpose of this study is to give a preliminary assessment of the advisability of thiosulfate leaching in the extraction of gold from ores on a laboratory scale. The experimental work has allowed for a study into the effects that arise from: The concentration of the leaching agent, impress current and the ratio $\mathrm{S}: \mathrm{L}$ on the process of gold extraction. The leaching of gold in a solution in the presence of a carbon disulfide electrode takes place with high intensity. Furthermore the gold can then be extracted from the solution by sorption.

It is found that in solutions of electrochemical leaching with a sodium thiosulfate concentration of 2.0 $\mathrm{mg} / \mathrm{dm}^{3}$, a current density of $200 \mathrm{~A} / \mathrm{m}^{2}, \mathrm{~S}: \mathrm{L}=1: 4$ and a temperature of $40^{\circ} \mathrm{C}$ the extent of the gold extraction reaches values of up to $80 \%$, as in the case of conventional cyanidation.
As a result of studies, the use of sodium thiosulfate as a solvent in the process of electrochemical leaching in order to increase the process selectivity and increase the degree of extraction of metals can be recommended for the extraction of metals from refractory materials.

One of the reasons for the low extraction ratio of noble metals from solutions is the presence of impurity metals in the leaching solutions. It was discovered that the efficiency of the sorption process of noble metals from electrochemical leaching solutions (sodium thiosulfate) is higher than from aqueous chemical leaching solutions. As a result, the selective extraction of metals and the absence of copper and iron directly increase the affinity of gold to the anion exchanger AM-2B.

\section{Acknowledgment}

The authors gratefully acknowledge the financial support of the research by the Science Committee of Ministry of Education and Science of the Republic of Kazakhstan.

\section{Author's Contributions}

Bagdaulet Kenzalyevich Kenzhaliyev: Designed the research plan, participated in the results analysis, contributed to the reviewing of the article critically.

Zamzagul Duisenovna Dosymbaeva and Renata Ramilevna Iskhakova: Designed and performed experiments, contributed in the development of the conceptual framework.

Essen Nurgalievich Suleimenov: Organized the study, data collection of the study sample, analysis and writing of the manuscript.

\section{Ethics}

The authors have no conflicts of interest in the development of the research and publication of this article.

\section{References}

Abbruzzese, C., P. Fornaria, R. Massiddaa, F. Vegliòb and S. Ubaldini, 1995. Thiosulphate leaching for gold hydrometallurgy. Hydrometallurgy, 39: 265-276. DOI: 10.1016/0304-386X(95)00035-F

Adams, M.D., 2005. Advances in Gold Ore Processing. 1st Edn., Elsevier, Amsterdam, ISBN-10: 0080459080, pp: 1076.

Aylmore, M.G. and D.M. Muir, 2001. Thiosulfate leaching of gold-a review. Miner. Eng., 14: 135-174. DOI: 10.1016/S0892-6875(00)00172-2

Aylmore, M.G., 2001. Treatment of a refractory goldcopper sulfide concentrate by copper ammoniacal thiosulfate leaching. Miner. Eng., 14: 615-637. 
Balaz, P., J. Ficeriova, E. Boldizarova, M. Haber and S. Jelen et al., 2000. Thiosulphate leaching of gold from a mechanochemically pretreated complex sulphide concentrate. Proceedings of the 21 International Mineral Processing Congress, (MPC' 00), Rome, pp: A6-74-A6-81.

Breuer, P.L. and M.I. Jeffrey, 2000. Thiosulfate leaching kinetics of gold in the presence of copper and ammonia. Miner. Eng., 13: 1071-1081. DOI: $10.1016 / \mathrm{S} 0892-6875(00) 00091-1$

Feng, D. and J.S. Van Deventer, 2002. Leaching behaviour of sulphides in ammoniacal thiosulphate systems. Hydrometallurgy, 63: 189-200. DOI: $10.1016 / \mathrm{S} 0304-386 \mathrm{X}(01) 00225-0$

Grosse, A.C., G.W. Dicinoski, M.J. Shaw and P.R. Haddad, 2003. Leaching and recovery of gold using ammoniacal thiosulfate leach liquors (a review). Hydrometallurgy, 692: 1-21. DOI: $10.1016 / \mathrm{S} 0304-386 \mathrm{X}(02) 00169-\mathrm{X}$

Kenzhaliev, B., 2014. Electrochemical method for extracting non-ferrous and precious metals from refractory materials using combined reactions. Proceedings of the 15th Topical Meeting of the International Society of Electrochemistry. Interfacial Electrochemistry at Atomic, Molecular and Nanoscale Domains (Niagara Falls, Canada).

Kholmogorov, A.G., O.N. Kononova, G.L. Pashkov and Y.S. Kononov, 2002a. Thiocyanate solutions in gold technology. Hydrometallurgy, 64: 43-48. DOI: $10.1016 / \mathrm{S} 0304-386 \mathrm{X}(02) 00005-1$

Kholmogorov, A.G., O.N. Kononova, G.L. Pashkov and Y.S. Kononov, 2002b. Sorption recovery of gold thiosulphate complexes. Chinese J. Chem. Eng., 10: 123-127.

Lee, H.Y., S.G. Kim and J.K. Oh, 1997. Cementation behavior of gold and silver onto $\mathrm{Zn}, \mathrm{Al}$ and $\mathrm{Fe}$ powders from acid thiourea solutions. Canadian Metallurgical Q., 36: 149-155.

DOI: $10.1016 / \mathrm{S} 0008-4433(97) 00004-9$

McNulty, T., 2001. Cyanide substitutes. Mining Magazine, 184: 256-261.
Parga, J.R., J.L. Valenzuela and J.A. Díaz, 2012. New Technology for Recovery of Gold and Silver by Pressure Cyanidation Leaching and Electrocoagulation. INTECH Open Access Publisher, ISBN-10: 9533078987.

Qingshuang, S., W. Dequan and C. Jinju, 1995. New method of extracting gold and silver from high silver-gold concentrates. Trans. Nonferrous Metals Society China, 5: 50-53.

Salarirad, M.M. and A. Behnamfard, 2011. Fouling effect of different flotation and dewatering reagents on activated carbon and sorption kinetics of gold. Hydrometallurgy, 109: 23-28. DOI: $10.1016 /$ j.hydromet.2011.05.002

Tremblay, L., G. Deschenes, E. Ghali, J. McMullen and M. Lanouette, 1996. Gold recovery from a sulphide bearing gold ore by percolation leaching with thiourea. Int. J. Mineral Process., 48: 225-244. DOI: 10.1016/S0301-7516(96)00029-4

Ubaldini, S., P. Fornari, R. Massidda and C. Abbruzzese, 1998. An innovative thiourea gold leaching process. Hydrometallurgy, 48: 113-124. DOI: 10.1016/S0304-386X(97)00076-5

Vignes, A., 2011. Extractive Metallurgy 3: Processing Operations and Routes. 1st Edn., John Wiley and Sons, Inc., Hoboken, New Jersey, ISBN-10: 1118617029 , pp: 352.

Yao, S.Z., F.J. He and L.H. Nie, 1992. Piezoelectric determination of traces of thiourea. Analytica Chimica Acta, 268: 311-314. DOI: $10.1016 / 0003-2670(92) 85226-\mathrm{V}$

Zhou, J., M. Zhou, P. Zhu and L. Kunfang, 2009. Method for leaching gold mine by electrochemistry oxidation method.

Zipperian, D. and S. Raghavan, 1988. Gold and silver extraction by ammoniacal thiosulfate leaching from a rhyolite ore. Hydrometallurgy, 19: 361-375. DOI: $10.1016 / 0304-386 \times(88) 90041-2$ 